\title{
Impact of testimonial evidence as a function of witness characteristics
}

\author{
LUIS T. GARCIA \\ Middlebury College, Middlebury, Vermont 05753 \\ and \\ WILLIAM GRIFFITT \\ Kansas State University, Manhattan, Kansas 66502
}

\begin{abstract}
Eighty undergraduate males and females participated in a 2 by 2 factorial design to investigate the impact of a witness's testimony on a simulated juror's decision task as a function of the likableness of the witness. It was hypothesized that: (1) ratings of the defendant's guilt would be influenced by the characteristics of the witnesses, that is, the testimony of a likable witness would have more impact than the testimony of a dislikable witness; and (2) ratings of a witness's credibility would be similarly affected-a likable witness would be believed more than a dislikable witness. Results indicated support for the hypotheses. An additional unexpected finding was that the credibility ratings of the witnesses were also affected by the opposing witness's description. The results were mainly discussed in terms of a reinforcement model of evaluative responses, although some limitations were pointed out.
\end{abstract}

In recent years, social psychologists have shown an increasing interest in the area of judicial decision making. This is evidenced by the number of articles published in this area, both in professional journals (Gerbasi, Zuckerman, \& Reis, 1977) and in popular magazines. As Gerbasi et al. point out, the majority of this research has focused on the effects of extralegal variables upon simulated jury decisions.

One variable that has been neglected in this area of research is the source of the evidence. In a trial, jurors do not always believe all the evidence that is presented before them (Kalven \& Zeisel, 1966). This is especially obvious in trials where conflicting testimony is presented. In this case, when jurors reach a verdict, it is probably because they chose to believe the testimony of one witness and disbelieve the testimony of another. In a trial, the source of the evidence or testimony is available to the jurors, and thus it provides a basis for jurors to make credibility judgments. The purpose of this study, therefore, was to study the characteristics of witnesses which influence the credibility of their testimony and the impact of such testimony on judgments of guilt.

McGuire (1969), in reviewing the literature of attitude change, states that a certain amount of evidence can be found in support of the hypothesis that the more a subject likes the source of a persuasive message, the more the subject will change his belief toward the position the source is advocating, although in the majority of these studies the subjects' perceptions of the

This report is based in part on a Master's thesis completed by the first author under the direction of the second author. speaker's credibility have not been directly assessed.

There are, however, some major differences between the procedures used to study attitude change and those needed to study the credibility of a witness which would limit the inferences that one can draw from one to the other. In the former, the speaker is actively trying to persuade the audience to his point of view. Supposedly, in the latter situation this is not the case. The witness is merely reporting his perceptions of some event, with no interest in the outcome. Second, in attitude change studies the subjects have formed an attitude concerning the topic in question before the speaker makes his attempt at persuasion. In the courtroom, the jurors may or may not have a preconceived opinion of whether the defendant is guilty. Finally, in attitude change studies the communication is usually argumentative rather than factual, while the reverse is presumably true in the case of a witness's testimony.

\section{METHOD}

\section{Subjects}

The subjects in this experiment were 80 introductory psychology students (44 females and 36 males) who received extra credit for their participation. ${ }^{1}$

\section{Procedure}

The subjects, who were run in groups, were taken to the experimental room and given a booklet containing the instructions, the details of the incident, the testimony of the witnesses along with their descriptions, and, finally, the various dependent measures.

The subjects were presented with the description of a crime that consisted of a modified version of an automobile-pedestrian accident previously used by Landy and Aronson (1969). The 
incident was varied slightly so that the key question at the trial became whether the defendant had run a red light at the time he struck the victim. It was also added that two eyewitnesses had been present at the scene of the incident.

After the subjects read the description of the accident, they were presented with excerpts from the interrogation of the witnesses. The questions posed to the witnesses were identical. Since the prosecution traditionally precedes the defense in presenting its case, all subjects read the prosecution witness's testimony first along with his description, followed by the defense witness's testimony and his description.

The testimony of the prosecution witness essentially stated that the defendant had run the red light, while the defense witness testified to the contrary. The descriptions of the witnesses followed their testimony and consisted of either five positive or five negative character traits presented in the context of narratives describing the competence of the witnesses. The narratives were presented in the form of reports from a psychologist who was supposedly observing the trial.

We are aware that formal presentations of evidence of this type clearly would be inadmissible in a real trial. The character traits were presented in this format to provide subjects a basis on which to form impressions of the witnesses; impressions that jurors in a real trial would be likely to form on the basis of observations of the witnesses' behaviors.

The character traits were obtained from Anderson's (1968) likableness norms. Since in one condition both witnesses were described positively and in another condition both were described negatively, two sets of positive traits and two sets of negative traits were selected. Three criteria for selection of traits were employed: (1) those traits that logically implied anything about the veracity of the witnesses were eliminated (i.e., honest, sincere); (2) the positive (likable) and negative (dislikable) traits were chosen so that they were approximately equal distance above and below the neutral rating point; and (3) the two sets of positive traits were chosen so that their mean ratings were not significantly different. The same criteria were utilized in the selection of the two sets of negative traits.

The experiment was thus a 2 by 2 factorial design. The factors were description of the prosecution witness (positive or negative) and description of the defense witness (positive or negative).

After the subjects read the questioning of the witnesses, they were asked to make ratings of guilt of the defendant on a 7-point scale ( 1 = not guilty, 7 = guilty). They were also asked to sentence the defendant from 1 to 25 years of imprisonment and to make appropriate recommendations of parole. Impressions of the defendant were obtained by means of a semantic differential scale with the following adjectives: attractiveunattractive, cold-warm, worthy-unworthy, likable-dislikable.

Attraction toward the witnesses was measured by the use of the interpersonal judgment scale (Byrne, 1971). Additionally, each witness was rated on a semantic differential scale with the following items: honest-dishonest, reliable-unreliable, trustworthy-untrustworthy, biased-unbiased. These were summed to yield a single score, which was taken as an index of perceived credibility.

\section{RESULTS}

\section{Manipulation Checks}

In order to assess the effectiveness of the character descriptions in manipulating attraction, scores on the interpersonal judgment scale (items 5 and 6 ) were subjected to a 2 by 2 analysis of variance. Results indicated that the mean attraction rating for the prosecution witness when described positively was 9.7 and when described negatively, $5.8 \quad[F(1,76)=69.00, p<.001]$. The means for the defense witness were 11.00 when described positively and 6.3 when described negatively $[\mathrm{F}(1,76)=110.17, \mathrm{p}<.001]$.

In the condition where both witnesses were described positively, a direct-difference $t$ test was run to see whether the two sets of positive traits had differential effects on attraction. Surprisingly, it was found that the attraction scores did indeed differ significantly $[t(19)=3.33, p<.01]$, with the defense witness being liked more $(M=10.70)$ than the prosecution witness $(M=9.20)$. A similar analysis was conducted to determine whether the two sets of negative traits had different effects on attraction. The results revealed a nonsignificant trend $[\mathrm{t}(19)=1.90, \mathrm{p}<.10]$, the defense witness being liked more $(M=6.70)$ than the prosecution witness $(\mathrm{M}=6.10)$.

\section{Credibility and Jury Decisions}

Each of the five measures of credibility and their sum score were analyzed separately. For the prosecution witness, all six analyses revealed a main effect for positivity of the description. When the prosecution witness was described in likable terms, he was rated as less biased, more honest, reliable, trustworthy, and believable than when he was described as unlikable (all ps $<.001$ ). Ratings of the credibility of the defense witness were similarly affected by his description (all ps $<.025$ ). The mean summed credibility ratings are presented in Table 1.

Interestingly, the prosecution witness was rated as more credible on the sum score of the five ratings when the defense witness was negatively described than when he was positively described $[\mathrm{F}(1,76)=4.82, \mathrm{p}<.05]$.

The credibility of the defense witness was also affected by the description of the prosecution witness. On the sum of the five ratings, the defense witness was perceived more credible when the opposing witness was described negatively $[F(1,76)=5.33, p<.05]$.

As was with the attraction measures, direct difference $t$ tests on credibility ratings were conducted in the conditions where both witnesses were similarly described. These results paralleled those of the attraction

Table 1

Mean Ratings of Defendant's Guilt and Witnesses' Credibility as a Function of Witnesses' Descriptions

\begin{tabular}{|c|c|c|c|c|}
\hline \multicolumn{2}{|c|}{ Witnesses' Descriptions } & \multirow{2}{*}{$\begin{array}{l}\text { Mean Ratings } \\
\text { of Guilt }\end{array}$} & \multicolumn{2}{|c|}{$\begin{array}{c}\text { Credibility Ratings } \\
\text { of Witnesses }\end{array}$} \\
\hline $\mathrm{P}$ & D & & $\mathbf{P}$ & $\mathrm{D}$ \\
\hline Positive & Positive & 3.25 & 22.10 & 25.20 \\
\hline Positive & Negative & 4.10 & 26.00 & 17.80 \\
\hline Negative & Positive & 2.80 & 16.10 & 27.00 \\
\hline Negative & Negative & 3.45 & 16.80 & 19.80 \\
\hline
\end{tabular}

Note $-P=$ prosecution; $D=$ defense. Credibility ratings are expressed such that the higher the rating, the more credible the witness was perceived. 
scores; in both cases the defense witness was rated as more credible (on the sum of the five ratings) (ps $<.01$ ).

The guilt, sentencing, and parole ratings were each submitted to separate analyses of variance. The mean guilt ratings as a function of the witnesses' descriptions are depicted in Table 1. As expected, two main effects for the character descriptions were present. The subjects were more certain of the defendant's guilt when the prosecution witness was characterized positively rather than negatively and when the defense witness was characterized negatively rather than positively. The $F$ value for the description of the prosecution witness was $F(1,76)=6.79(p<.01)$, and for the defense witness, $F(1,76)=12.62(p<.01)$.

Internal comparisons of the guilt ratings presented in Table 1 revealed that the ratings in the two conditions where both witnesses were characterized in similar terms were not significantly different from each other. In addition, the ratings in the two conditions where the defense witness was described positively did not differ significantly. All other ratings were reliably different from each other.

Analyses of the sentencing and parole recommendations did not reveal any reliable differences across conditions.

\section{DISCUSSION}

The results on the credibility measures clearly indicate that when the witness, whether prosecution or defense, is characterized in likable terms, he is perceived as more credible than when he is described in nonlikable terms. These results, which are reflected by the guilt ratings, can be interpreted in terms of Byrne and Clore's (1970) reinforcement model of evaluative responses. According to this model, evaluative responses are mediated by an implicit affective response which is evoked by the liked (attractive) stimulus. Within-cells correlations between attraction scores and credibility ratings support the notion that attraction toward the witnesses is mediating the evaluative judgments. These correlations were computed within each condition, converted to $\mathrm{z}$ scores, averaged, and then tested for significance (McNemar, 1962). The resulting $\mathrm{z}$ scores for the correlations computed for both the prosecution witness $(\mathrm{z}=2.66, \mathrm{p}<.01)$ and the defense witness $(\mathrm{z}=4.00, \mathrm{p}<.01)$ were statistically significant.

The credibility ratings of both witnesses were also affected by the opposing witness's description, while the attraction ratings were not. This finding is not readily interpretable by the attraction-reinforcement model. Examination of Table 1 reveals that this result was due to the fact that when the two witnesses were described in opposite terms, the credibility ratings were extreme. What seems to be happening can be described as a two-step process. First, according to a reinforcement model, the subject, as a result of attraction, perceives one of the witnesses as credible. Second, since the two witnesses disagree on their perception of the accident, the subject logically infers that the other witness is less believable.

The results for the guilt variable were in line with the stated predictions. The results clearly show that the subjects base their decisions of guilt on the testimony of whichever witness is described in likable terms. The impact that witness has on a juror seems to be a function of how the juror views that witness's character.

Examination of the guilt ratings in Table 1 reveals that, even when the two witnesses were described in similar terms, the subjects' mean rating was below the midpoint in the scale, indicating a "not guilty" verdict. This finding is predictable, taking into account the fact that in the conditions where both witnesses were similarly described, the defense witness (unintentionally) was liked more and seen as more credible than the prosecution witness. This difference could have been due to a number of factors that were confounded in this experiment, such as order of presentation of evidence or sets of character traits. Finally, it is possible that the difference was due to the fact that the defense witness, other things being equal, is generally liked more than the prosecution witness. There is at this moment no evidence for choosing one of these factors as being more likely than the others.

Recommendations for sentencing did not reveal any significant differences across conditions. This is understandable, since in this study no information was given as to the character of the defendant, and this is the variable which has been found to influence sentencing in previous experiments (Griffitt \& Jackson, 1973; Kaplan \& Kemmerick, 1974; Mitchell \& Byrne, 1973).

\section{Conclusions}

This study joins a growing body of recent research in demonstrating the important role of extralegal variables in simulated judicial decisions. While the previous literature reports many instances where decisions concerning defendants were affected by the defendant's own characteristics, the present study shows that decisions about defendants can be influenced even though no information is given about them, the extralegal variable being the characteristics of the source of the evidence. Thus, even when subjects have a legally relevant basis on which to form their decisions, the impact of such evidence is a function of legally irrelevant variables.

Berg and Vidmar (1975), in studying the role of juror characteristics in persuasion in the courtroom, noted that previous research in this area has focused on structural characteristics of the evidence and on presentation of the evidence. The present experiment shows that characteristics of the source of the evidence, such as attractiveness, should be considered as an important variable in this regard.

\section{REFERENCES}

Anderson, N. H. Likableness ratings of 555 personalitytrait words. Journal of Personality and Social Psychology, 1968, 20, 272-279.

BERG, K. S., \& VIDMAR, N. Authoritarianism and recall of evidence about criminal behavior. Journal of Research in Personality, 1975, 9, 147-157.

Byrne, D. The attraction paradigm. New York: Academic Press, 1971.

Byrne, D., \& Clore, G. L. A reinforcement model of evaluative responses. Personality: An International Journal, 1970, 2, 103-128.

Gerbasi, K. C., Zuckerman, M., \& Reis, H. T. Justice needs a new blindfold: A review of mock jury research. Psychological Bulletin, 1977, 84, 323-345.

Griffitt, W., \& JACKson, T. Simulated jury decisions: The influence of jury-defendant attitude similarity-disimilarity. Social Behavior and Personality, 1973, 1, 1-7.

Kalven, H., \& Zeisel, H. The American jury. Boston: Little, Brown, 1966.

Kaplan, M. F., \& Kemmerick, G. D. Juror judgment as information integration: Combining evidential and nonevidential information. Journal of Personality and Social Psychology, 1974, 30, 493-499.

LANDY, D., \& ARonson, E. The influence of the character of the criminal and his victim on the decisions of simulated 
jurors. Journal of Experimental Social Psychology, 1969, 5. 141-152.

McGuire, W. J. The nature of attitudes and attitude change. In G. Lindzey \& E. Aronson (Eds.), Handbook of social psychology (Vol. 3). Reading: Addison-Wesley, 1969. Pp. 136-315.

McNemar, Q. Psychological statistics (3rd. ed.): New York: John Wiley, 1962.

Mitchell, H., \& BYrne, D. The defendant's dilemma: Effects of jurors' attitudes and authoritarianism on judicial decisions. Journal of Personality and Social Psychology, 1973, 25, 123-129.

\section{NOTE}

1. The subjects were originally divided into high and low authoritarians, but since no authoritarian differences were found, the data were collapsed across this variable.

(Received for publication September 26, 1977.) 